\title{
EFFECT OF HEAT TREATMENT ON MICROSTRUCTURE AND PROPERTIES OF ENDODONTIC NITI INSTRUMENTS
}

\author{
${ }^{1}$ Michal ŠTENCEK, ${ }^{1}$ Monika LOSERTOVÁ, ${ }^{2}$ Dalibor MATÝSEK, ${ }^{1}$ Jaromír DRÁPALA, \\ 'Veronika JORDANOVOVÁ \\ ${ }^{1}$ VSB - Technical University of Ostrava, Faculty of Materials Science and Technology, Ostrava, \\ Czech Republic, EU, michal.stencek@vsb.cz \\ ${ }^{2}$ VSB - Technical University of Ostrava, Faculty of Mining and Geology, Ostrava, Czech Republic, EU \\ https://doi.org/10.37904/metal.2019.962

\begin{abstract}
The shape memory effects and superelastic behavior of Ni-rich $\mathrm{NiTi}$ alloys (> 50.6 at\% $\mathrm{Ni}$ ) are significantly dependent on microstructural changes during heat treatment. Furthermore, it is also generally known that thermal treatment of $\mathrm{Ni}$-rich $\mathrm{NiTi}$ alloys induces diffusion processes that lead to precipitation. Depending on temperature and holding time, several types of precipitates can be formed in microstructure of the alloy. microstructural changes can have a major impact on the martensitic transformation in NiTi alloys and, essentially, on the transformation temperatures. In addition, the precipitation of secondary phases can also contribute to a substantial increase in the strength of NiTi alloys. Another critical factor affecting the properties of these materials is the composition. The experimental samples of NiTi alloy with 50.7 at\% Ni were subjected to heat treatment. The thermal regimes consisted of aging treatment at 300,350 and $400{ }^{\circ} \mathrm{C}$ for $0.5 \mathrm{~h}$ followed by air cooling. The microstructures before and after the heat treatment were observed by optical microscopy.
\end{abstract} \\ Assumed transition path is: metastable $\mathrm{Ni}_{4} \mathrm{Ti}_{3}$ - metastable $\mathrm{Ni}_{3} \mathrm{Ti}_{2}$ - stable $\mathrm{Ni}_{3} \mathrm{Ti}$. Thus, these and other \\ The study was completed by microhardness measurement and X-ray analysis. The obtained results show that \\ the aging temperatures led to microstructural and microhardness changes for the investigated alloy.
}

Keywords: NiTi alloy, heat treatment, aging, microstructure

\section{INTRODUCTION}

The NiTi-based binary alloys, commonly called to as "Nitinols", belong to a group of "memory materials", sometimes also called to as "smart alloys". In terms of crystal lattice and structure are these materials intermetallic compounds. From the binary diagram, the occurrence of this alloy can be determined in the range of about $49-55$ at $\% \mathrm{Ni}$, depending on temperature. These materials exhibit shape memory effects and superelasticity, under certain thermomechanical and test conditions. These unique properties depend heavily on the chemical composition and thermomechanical processing of the alloy. Other properties, in addition to the shape memory behavior, are also very good corrosion resistance, biocompatibility, advantageous strength/density ratio or high damping ability. For these properties, NiTi alloys are nowadays mostly used in medicine. Especially, in the fields of dentistry (root canal instruments, braces), orthopedics (plates, nails) or cardiac surgery (stents, catheters).

$\mathrm{NiTi}$ endodontic rotary instruments utilize particularly superelastic behavior, corrosion resistance and biocompatibility. Corrosion resistance and biocompatibility are due to the formation of a thin surface oxide layer of $\mathrm{TiO}_{2}$. Superelasticity is then characterized by nonlinear reversible deformation behavior at temperatures above $A_{f}$ and below $M_{d}$. The magnitude of this reversible deformation can reach up to $10 \%$ under certain conditions. This behavior is caused by the formation of stress-induced martensite, resulting from mechanical loading and subsequent austenitic (reversible) transformation after unloading [1]. Unlike the shape memory effect, in the case of superelasticity, austenite $\Leftrightarrow$ martensite transformation occurs only due to the applied load, not by the change of temperature. However, certain conditions must be maintained to achieve 
superelastic behavior. A prerequisite is the existence of a matrix in a completely austenitic state. Other factors that may affect the subsequent return to the original shape are temperature, heat treatment condition, stress mode or microstructure (especially texture) [1].

An important factor is also the chemical composition of the alloy. In binary NiTi alloys containing $<50.4$ at\% $\mathrm{Ni}$ (almost equiatomic alloys), superelasticity is observed in samples which have been cold-formed and subsequently annealed at temperatures below their critical recrystallization temperature. The annealing temperature to achieve optimal superelastic behavior is typically in the range of about $400-500{ }^{\circ} \mathrm{C}$ according to various authors. For so-called "Ni-rich" alloys, i.e. alloys containing $>50.6 \mathrm{at} \% \mathrm{Ni}$, superelastic behavior can be achieved during aging (in the range of about $350-450{ }^{\circ} \mathrm{C}$ ) after previous solution treatment. Aging at this temperature range then promotes the formation of $\mathrm{Ni}$-rich precipitates such as $\mathrm{Ni}_{4} \mathrm{Ti}_{3}$ or $\mathrm{Ni}_{3} \mathrm{Ti}_{2}$. $\mathrm{The}$ common feature of both of these superelastic materials is the increased yield strength. However, in the first case it is a dislocation hardening, in the second case it is then precipitation hardening [2]. The most commercially used superelastic NiTi alloy contains approximately 50.8 at\% $\mathrm{Ni}$ [1].

Thus, thermal or thermomechanical treatment and the specific chemical composition of the alloy are essential parameters that determine the final properties of these alloys. Thus, the aim of this work was the study of microstructure of endodontic NiTi instruments before and after different heat treatment.

\section{EXPERIMENTAL}

The experimental material included non-machined endodontic NiTi instruments, from commercially available NiTi SE508 alloy. In terms of chemical composition, it is "Ni-rich" alloy containing 50.7 at\% Ni. The specific chemical composition is shown in Table 1.

Table 1 Chemical composition of NiTi SE508 alloy [3]

\begin{tabular}{ll}
\hline Element & Amount (wt\%) \\
\hline Nickel & 55.8 \\
Titanium & rest \\
Oxygen & $\leq 0.05$ \\
Carbon & $\leq 0.02$ \\
\hline
\end{tabular}

Samples were heat treated at 300,350 and $400{ }^{\circ} \mathrm{C}$ for $0.5 \mathrm{~h}$ followed by air cooling. The time to reach a particular temperature was about $0.5 \mathrm{~h}$ for all samples. The LAC chamber furnace with resistance heating was used for heating. A diagram of the temperature modes is shown in Figure 1. One sample was left in its original state for a comparison.

All samples were then cold mounted into LevoCit (Struers) resin. Subsequent metallographic preparation consisted of grinding, polishing and etching. Grinding was performed on a LaboPol-5 apparatus (Struers) equipped with the LaboForce-3 semi-automatic device with simultaneous use of $\mathrm{SiC}$ abrasive papers and water. The grinding time ranged from 2-3 minutes for the specific grain size of applied SiC abrasive paper. Polishing was performed on the same apparatus, but on canvas in a suspension of $\mathrm{Al}_{2} \mathrm{O}_{3}$ with a particle size $1 \mu \mathrm{m}$ and then $0.3 \mu \mathrm{m}$. The polishing time ranged from 6-8 minutes for each grain size. The final step of metallographic preparation was etching, using a mixed solution of acids: $\mathrm{CH}_{3} \mathrm{COOH}(99.8 \%), \mathrm{HF}(38-40 \%)$ and $\mathrm{HNO}_{3}(65 \%)$ with a 3:3:5 ratio. The polished samples were immersed in the acid solution for 4-5 s. The microstructure of etched samples was then examined by OLYMPUS GX51 inverse metallographic microscope. All images correspond to longitudinal cuts. For better depth of filed, aperture diaphragm was used in most images. 
FUTURE-TECH FM-100 automatic microhardness tester with FM-ARS900 control unit was used to determine the Vickers microhardness. Due to longitudinal shape of the samples, the microhardness was measured in the central area parallel to the edge of the sample in the range of 5 punctures. The load was $0.1 \mathrm{~kg}$.

Bruker D8 Advance X-Ray Diffraction apparatus was used to detect present phases in the microstructure of the samples. Measurement conditions: accelerating voltage $40 \mathrm{kV}$, anode current $40 \mathrm{~mA}$, step mode - step 0.0147 , range $5-80^{\circ}$, detailed measurement of the spectrum in the range from $38-47^{\circ}$, where appropriate conditions exist.

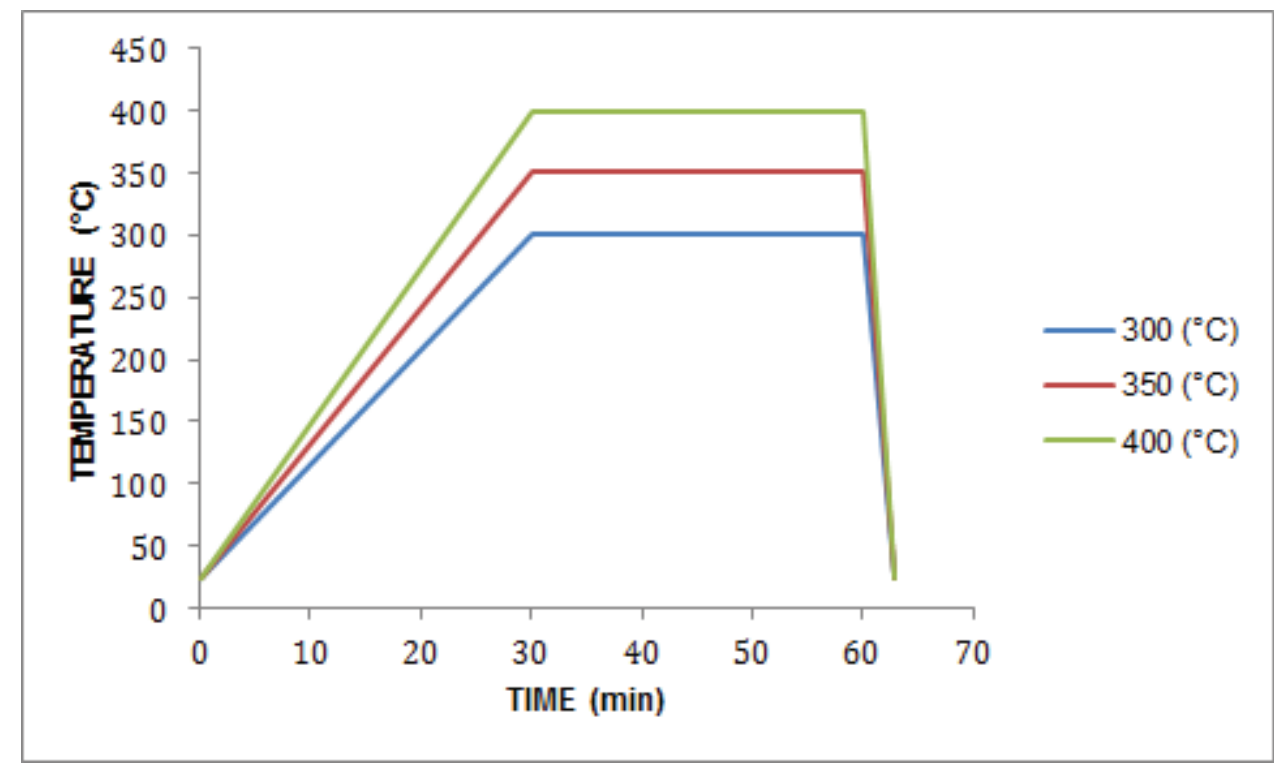

Figure 1 Schematic illustration of thermal treatment

\section{RESULTS AND DISCUSSION}

\subsection{Microstructural analysis}

Figure 2 shows the microstructures of endodontic NiTi instruments in front part of tools. The selected microstructural details are then shown in Figure 3.

The samples show different types of microstructures depending on the specific heat treatment modes. In general, the microstructure of the samples is composed of needle-like martensite with different spatial orientation, needle/plate thickness or length and the residual portion of the austenitic NiTi phase. It is possible to observe a microstructure formed by coarse martensitic plates, e.g. sample in initial state or heat treated sample at $400{ }^{\circ} \mathrm{C}$, to very fine martensitic needles, which essentially fill the entire sample volume (sample heat treated at $350{ }^{\circ} \mathrm{C}$ ). The highest degree of uniformity is then observed in sample heat treated at $300{ }^{\circ} \mathrm{C}$. The microstructure in this case is formed by martensitic needles arranged in individual packets.

It is also evident that in addition to the phases discussed above a further phase can be observed in the microstructure of all samples, especially at higher magnifications (Figure 3). This phase is in the form of aligned parallel lines (with the axis of the endodontic instrument) or as separate particles various shapes of sharp-edged character. The length of these formations achieves up to several tens of $\mu \mathrm{m}$ in some cases. Based on the knowledge of this issue and the works of other authors, e.g. [4,5], these objects can be designated as the $\mathrm{NiTi}_{2}$ particles. This assumption has been confirmed in our previous research by SEM images as well as EDX analysis. Thus, the presence of $\mathrm{NiTi}_{2}$ phase is observed in the microstructure of all samples, regardless of thermal treatment condition. Therefore, it can be assumed that the occurrence of this 
phase, due to the known origin and processing of samples, is already linked to the initial stages of production of the original material, which was subsequently used for the manufacture of endodontic instruments.
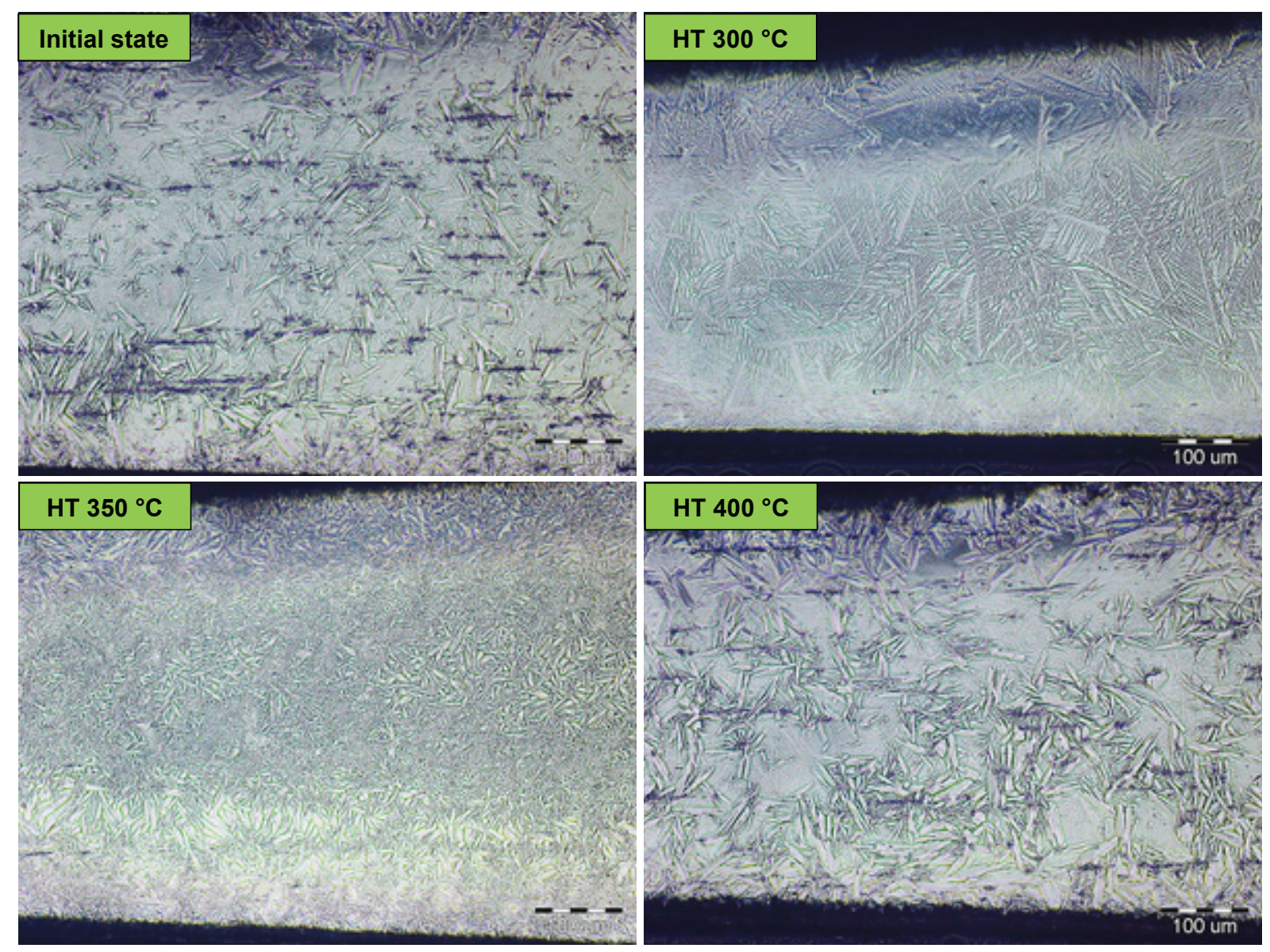

Figure 2 Optical micrographs of samples (in front part of tools) after different heat treatment modes

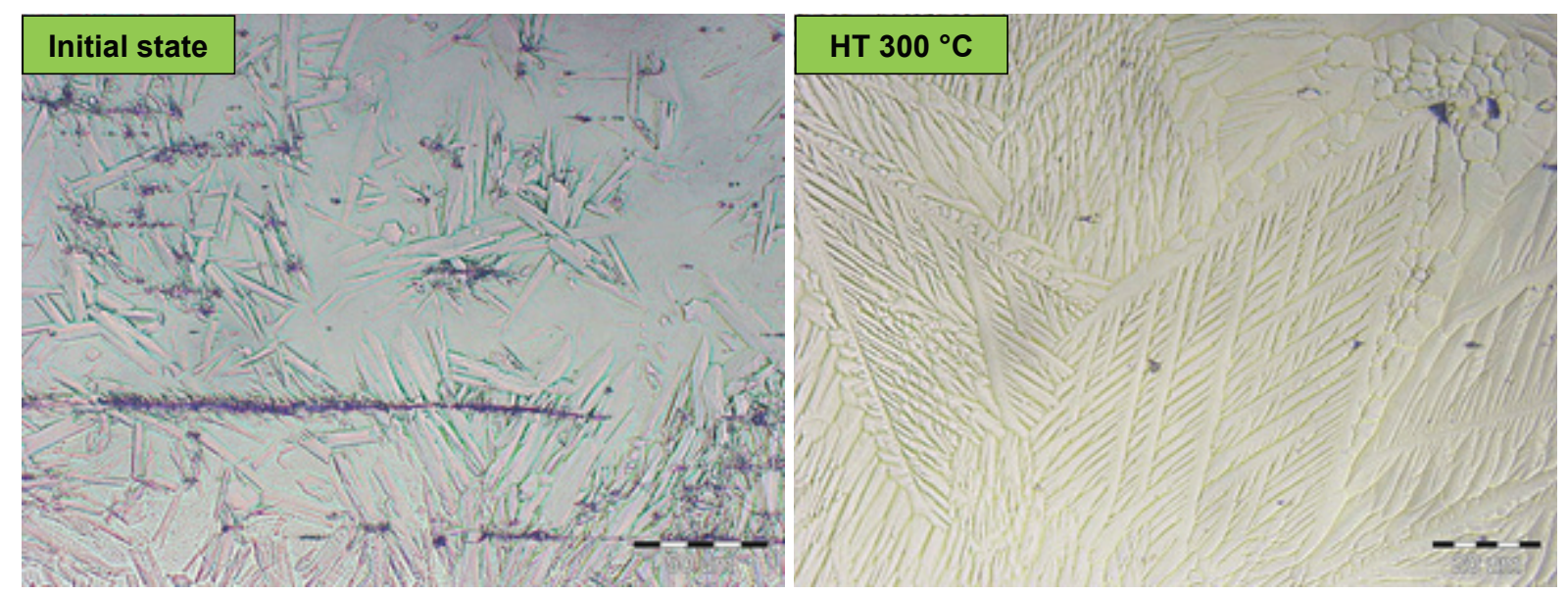

Figure 3 Optical micrographs of microstructural details of selected samples after different heat treatment modes

The endodontic NiTi instruments are subjected to significant rotation stress in practical use. Thus, the existence of a $\mathrm{NiTi}_{2}$ phase in instruments in the form of sharp-edged or deformed particles can be generally considered as negative. Fatigue cracks may then be initiated in use. As a result, this can lead to a complete 
violation of the instrument. In addition, at high rotational speeds, further degeneration of these particles cannot also be excluded.

\subsection{Microhardness}

The average Vickers microhardness values of HV 0.1 with a standard deviation $(\sigma)$ are summarized in Table 2. The values are in the range of approximately 370 to $410 \mathrm{HV} \mathrm{0.1.} \mathrm{Thus,} \mathrm{heat} \mathrm{treatment} \mathrm{had} \mathrm{some}$ effect on microhardness of NiTi instruments, but not critical. The lowest microhardness (373 HV 0.1) shows a sample heat treated at $400{ }^{\circ} \mathrm{C}$. This decrease in microhardness may be caused, for example, by recovery processes, which may occur at these elevated temperatures.

Table 2 Microhardness values HV 0.1 of samples

\begin{tabular}{lll}
\hline CONDITION & HV 0.1 & $\boldsymbol{\sigma}$ \\
\hline Initial state & 395 & 46.52 \\
HT $300\left({ }^{\circ} \mathrm{C}\right)$ & 390 & 13.70 \\
HT $350\left({ }^{\circ} \mathrm{C}\right)$ & 406 & 29.24 \\
HT $400\left({ }^{\circ} \mathrm{C}\right)$ & 373 & 29.29 \\
\hline
\end{tabular}

It is also necessary to remind the fact that a microhardness tester was used to measure hardness of the samples. Thus, during the measurement, the indentor could locally hit the different areas of the alloy, such as martensitic needles/plates, austenitic matrix or even $\mathrm{NiTi}_{2}$ particles. For this reason, it is necessary to consider the results as indicative.

\subsection{XRD analysis}

The X-ray diffraction patterns for the sample in initial state and the heat treated samples at 300 and $350{ }^{\circ} \mathrm{C}$ were very similar. In these XRD charts were detected phases: a-austenite NiTi and R-phase NiTi (rhombohedral variant of martensitic structure). The XRD chart for the sample heat treated at $400{ }^{\circ} \mathrm{C}$ was different. In addition to the phases discussed above, the presence of a particular variant of the martensitic phase, designated as P2/c, was also detected. Unfortunately, the necessary data from the own phase and structure database were not available for the martensitic phase. Thus, I was not possible to quantify the mutual proportion of individual structural components, only their presence. For a comparison, the XRD charts for sample in initial state and heat treated sample at $400{ }^{\circ} \mathrm{C}$ are shown in the Figure 4.
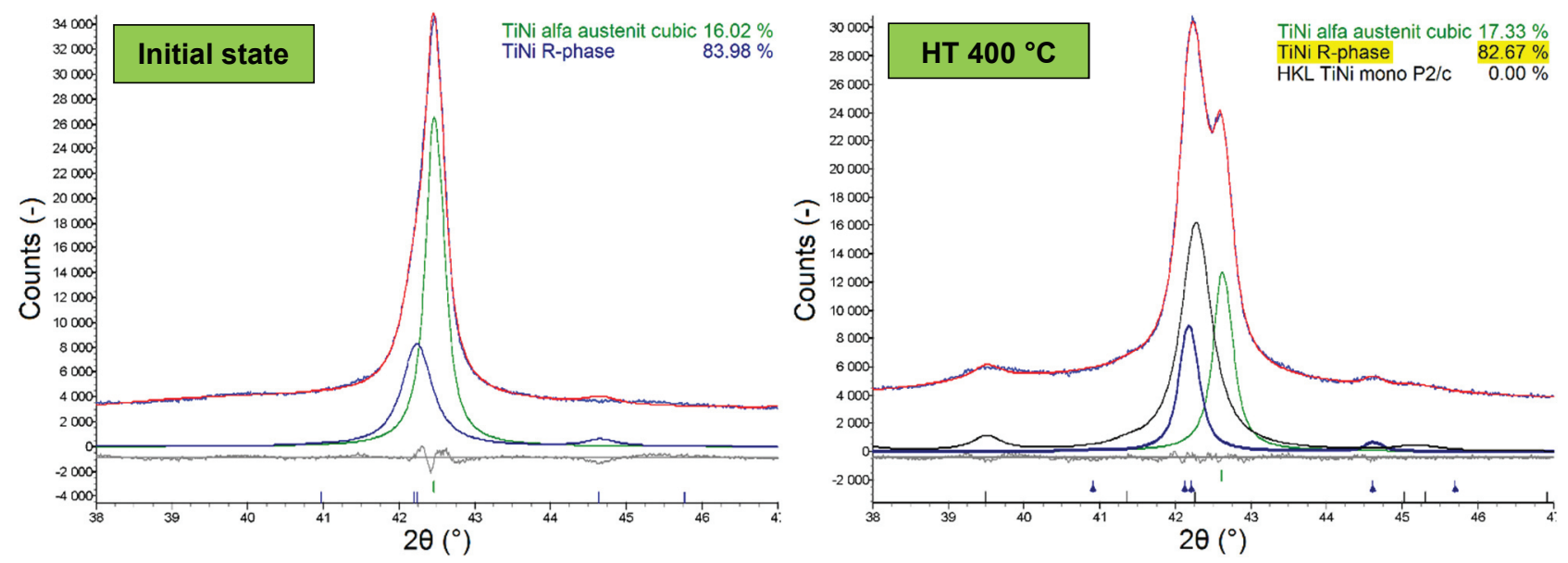

Figure 4 X-ray diffraction patterns of selected samples: initial condition and heat treated at $400{ }^{\circ} \mathrm{C}, 0.5 \mathrm{~h}$ 


\section{CONCLUSION}

The microstructural evolution of endodontic NiTi instruments (NiTi SE508 alloy) has been investigated, during heat treatment in the range of $300-400^{\circ} \mathrm{C}$, with following conclusions:

1) The microstructure of the samples is composed of needle-like martensite with different spatial orientation, needle/plate thickness or length and the residual portion of the austenitic NiTi phase. The selected heat treatment influences mainly the proportion of individual components or their morphology. It is possible to observe coarse martensitic plates (IS or $\mathrm{HT}$ at $400^{\circ} \mathrm{C}$ ) up to very fine martensitic needles which essentially fill the entire sample volume $\left(\mathrm{HT}\right.$ at $\left.350^{\circ} \mathrm{C}\right)$. The highest degree of uniformity is then observed for the $\mathrm{HT}$ at $300{ }^{\circ} \mathrm{C}$ (martensitic needles are arranged into individual packets). The occurrence of the $\mathrm{NiTi}_{2}$ phase was also observed, in the form of aligned parallel lines (with the axis of endodontic instruments) or separate particles of various shapes of sharp-edged character. The existence of this phase in the endodontic NiTi instruments may in use initiate fatigue cracks which can lead to a complete violation of the instrument.

2) The specific heat treatment modes had very low effect on the microhardness of the samples. The average values are in the range of approximately 370 to $410 \mathrm{HV} 0.1$. The lowest microhardness (373 HV 0.1) shows a sample heat treated at $400{ }^{\circ} \mathrm{C}$. This decrease in microhardness may be caused by recovery processes, which may occur at these elevated temperatures.

3) In the X-ray diffraction patterns of sample in IS and samples $\mathrm{HT}$ at 300 and $350{ }^{\circ} \mathrm{C}$ was detected the presence of phases: $\alpha$-austenite NiTi and R-phase NiTi (rhombohedral variant of martensitic structure). The XRD chart for the sample heat treated at $400{ }^{\circ} \mathrm{C}$ was different. In addition to the phases discussed above, the presence of a particular variant of the martensitic phase, designated as $\mathrm{P} 2 / \mathrm{c}$, was also detected.

\section{ACKNOWLEDGEMENTS}

This work has been realized in the framework of the following projects: L01203 "Regional Materials Science and Technology Centre - Feasibility Program", TH01020487 "Development Of Endodontic Tools”, RRC/10/2017 "Support for Science and Research in the Moravia-Silesia Region 2017", financed from the budget of the Moravian-Silesian Region and SGS projects SP2019/128 and SP2019/43.

\section{REFERENCES}

[1] ELAHINIA, Mohammad H., HASHEMI, Mahdi, TABESH, Majid and BHADURI, Sarit B. Manufacturing and processing of NiTi implants: A review. Progress in Materials Science [online]. 2012. vol. 57, no. 5, pp. 911-946 [viewed 2019-05-10]. Available from: DOI: 10.1016/j.pmatsci.2011.11.001. ISSN 00796425.

[2] LIU, Yinong and GALVIN, S.P. Criteria for pseudoelasticity in near-equiatomic NiTi shape memory alloys. Acta Materialia [online]. 1997. vol. 45, no. 11, pp. 4431-4439 [viewed 2019-05-10]. Available from: DOI: 10.1016/S1359-6454(97)00144-4.

[3] NITINOL PRODUCTS \& FRAMES: Nitinol Material Properties. Confluent Medical Technologies [online]. Fremont (California): Confluent Medical Technologies, 2019. [viewed 2019-05-12]. Available from: https://confluentmedical.com/capabilities/nitinol-component-manufacturing/

[4] BHAGYARAJ, J., RAMAIAH, K.V., SAIKRISHNA, C.N., BHAUMIK, S.K. and GOUTHAMA. Behavior and effect of Ti2Ni phase during processing of NiTi shape memory alloy wire from cast ingot. Journal of Alloys and Compounds [online]. 2013. vol. 581, pp. 344-351 [viewed 2019-05-13]. Available from: DOI: 10.1016/j.jallcom.2013.07.046.

[5] LOSERTOVÁ, M., ŠTENCEK, M., MATÝSEK, D., ŠTEFEK, O. a DRÁPALA, J. Microstructure evolution of heat treated NiTi alloys. IOP Conference Series: Materials Science and Engineering [online]. 2017. vol. 266 [viewed 2019-05-15]. Available from: DOI: 10.1088/1757-899X/266/1/012008. 